Reviews in Digital Humanities • Vol. 2, No. 3

\title{
Review: Furious Flower Digital Archive
}

Gabrielle Roth ${ }^{1}$

${ }^{1}$ University of Texas at Austin

Published on: Mar 08, 2021

DOI: $10.21428 / 3 \mathrm{e} 88 \mathrm{f} 64 \mathrm{f} .6632 \mathrm{e} 08 \mathrm{e}$

License: Creative Commons Attribution 4.0 International License (CC-BY 4.0). 


\section{Project}

Furious Flower Digital Archive

Project Leaders

Joanne V. Gabbin, James Madison University

The Furious Flower Poetry Center

Project URL

https://furiousflower.org/

\section{Project Reviewer}

Gabrielle Roth, University of Texas at Austin

\section{Project Overview}

\section{Joanne V. Gabbin}

The Furious Flower Digital Archive prototype is a result of a classroom-based digital humanities project at James Madison University. The class that built the prototype included five faculty and thirtythree undergraduate students from English, education, graphic design, and writing studies. The website showcases the entire proceedings of the first Furious Flower conference in 1994, the first-and one of the most prestigious - conferences dedicated to Black poetry in the world and supplements video and other archival materials from the conference with interpretive and educational media designed by the class. The archive prototype is a responsive website built in WordPress using the Foundation front-end framework. The final site has a stylesheet with 2967 lines of handwritten code and 95 unique web pages. Content developed for the site includes 529 transcribed video clips (approximately 55 hours of video), student-written biographies of 41 poets and eight critics, interactive content including a timeline that links poems to 21 historical events, and an interactive version of the original conference program with embedded video. An education portal leads to student and teacher resources that includes nine lesson plans aligned with reading, writing, and language Common Core Standards for English/Language Arts and the Virginia Standards of Learning.

The prototype was designed with three goals in mind: to help Furious Flower envision the possibilities of a digital archive, to attract potential funders, and accomplish these first two tasks in a way that fulfilled a central part of its mission as a center: to teach students the love of Black poetry. A "looks like" prototype (rather than a finished product with the requisite database integration) matched student skill levels and the limits of what can be accomplished during the timeframe of a 15-week semester. As Brandon T. Locke observes (2017), digital humanities classes provide students with skills 
beyond domain-specific content. Alongside a grounding in Black poetry, students in this course gained experience in areas such as web design, user experience, content management, and collaboration. Fittingly, the prototype had its official unveiling at the Furious Flower 25th Anniversary_ Celebration at the National Museum of African American History and Culture in 2019.

The limits of the prototype include a lack of time to undertake adequate user testing and the inability to scale the project because of its lack of integration with a professional-grade archival database. However, creating the prototype through a class project answered other challenges faced by regional, teaching-focused institutions, which rarely have the infrastructure, such as dedicated centers, budgets, and extensive staff, to support projects of this size and complexity (see Alexander and Frost Davis, 2012). Further, a prototype was useful to demonstrate proof of concept, as teachingfocused institutions are less likely to receive major grants from national funding sources such as the $\mathrm{NEH}$ (Godfrey and McCarthy, forthcoming). The prototype gave Furious Flower tangible evidence of the future archive's potential, while also demonstrating the pedagogical and methodological value of engaging undergraduates in digital humanities.

\section{References}

Alexander, Bryan, and Rebecca Frost Davis. "Should Liberal Arts Campuses Do Digital Humanities? Process and Products in the Small College World." Debates in the Digital Humanities, edited by Matthew K. Gold, 1st ed., University of Minnesota Press, 2012., https://dhdebates.gc.cuny.edu/read/untitled$\underline{88 c 11800-9446-469 b-a 3 b e-3 f d b 36 b f b d l e / s e c t i o n / d 61 c b 020-c 749-405 a-a b 59-63 f 8 d a 332425 \# c h 21 . ~}$

Godfrey, Mollie, and Seán McCarthy. “Black Women’s Lives Matter: Mapping Black Feminist Archival Recovery Projects." A/b: Auto/Biography Studies, forthcoming 2020.

Locke, Brandon T. "Digital Humanities Pedagogy as Essential Liberal Education: A Framework for Curriculum Development." Digital Humanities Quarterly, vol. 11, no. 3, Oct. 2017, http://www.digitalhumanities.org/dhq/vol/11/3/000303/000303.html.

\section{Project Review}

\section{Gabrielle Roth}

The Furious Flower Archive (FFA) is an interactive digital home for the digitized materials of the 1994 Furious Flower Poetry Conference sponsored by the Furious Flower Poetry Center (FFPC) and its founder, Dr. Joanne V. Gabbin. The FFPC provides access to a range of materials to educate, celebrate, and preserve the histories and traditions of Black poetry in the United States through their 
partnership with the James Madison University (JMU) Carrier Library Special Collections. The website acts as a digital archive of FFPC's collection, offering viewers the option to peruse materials by poet, collection highlights, or theme. It also provides users with the ability to explore the interactive program from the 1994 conference, which is valuable for educational use by teachers and for students working independently to learn more about Black poetry. This prototype for a digital archive also provides a proof-of-concept to use for soliciting funding.

One of the unique aspects of the project is its approach to presenting the work of the poets. The site features videos of poetry readings accompanied by text of the poems, most with annotations accessible through the hypothes.is plugin. Registered users can contribute annotations as well. Providing the option to review and add to annotations creates a digital conversation for the expanded community of the FFPC. The project's “Themes" section contextualizes Black poetry in America, providing a timeline of struggle tracing human and civil rights in the US from 1950 (when Gwendolyn Brooks was the first Black person to earn a Pulitzer Prize) to the first FFPC conference in 1994; the relationship between poetry and popular music developed by African Americans; and a renaissance of African American poetry. The FFPC's timeline successfully establishes an ontology of Black poetry and socio-cultural progress for Black Americans by mapping them simultaneously, illuminating what the "Timeline" page describes as "various dimensions of artistic freedom and the lengths that poets will go to achieve poetic expression." By using a WordPress site instead of a traditional digital archiving platform such as Omeka or Fedora, the project team has greater control over the front-end design and display of its archived content. Additionally, the project provides ample educational resources for use by teachers and students alike in the "Classroom" section of the site, upholding the American Historical Association's goal of using digital technologies for research and teaching pedagogy.

The digital archive was created through the collaboration of 33 students and six instructors across six disciplines at JMU who worked in project teams on the design, educational elements, history and topics, media and modes, and poet backgrounds to develop the site and its supplemental content. In addition to developing the prototype website, students in the "Innovating the Archives" course participated in writing workshops where they learned about the historical and cultural significance of African American poetry and wrote their own poetry connected to the collection, effectively furthering the FFPC's mission to educate and celebrate Black American poetry. The digital archive affords the FFPC expanded visibility for international users who are interested in Black American poetry by extending the reach of materials beyond participating critics and poets and scholars and researchers on-site at JMU.

\section{References}

AHA. (n.d.) "Guidelines for the Professional Evaluation of Digital Scholarship by Historians." American Historical Association. https://www.historians.org/teaching-and-learning/digital-history= 
resources/evaluation-of-digital-scholarship-in-history/guidelines-for-the-professional-evaluation-ofdigital-scholarship-by-historians. Accessed 08 November 2020.

Furious Flower Archive. Furious Flower Poetry Center. https://furiousflower.org/. Accessed 07 November 2020.

Gabbin, J. V. “Furious Flower: Introduction: Study Guide.” Newsreel. https://newsreel.org/guides/furious/introduc.htm. Accessed 20 November 2020.

James Madison University Furious Flower Poetry Center. "About Furious Flower." JMU.EDU, https://www.jmu.edu/furiousflower/about\%20us.shtml. Accessed 26 October 2020.

“Timeline: History, Witness, and the Struggle for Freedom in African American Poetry. (2019)." Furious Flower Poetry Center. https://furiousflower.org/timeline/. Accessed 20 November 2020. 